ERRATUM

\title{
GUEST EDITORIAL: Revised NIA-AA criteria for the diagnosis of Alzheimer's disease: a step forward but not yet ready for widespread clinical use - ERRATUM
}

\author{
Giovanni B. Frisoni, Bengt Winblad and John T. O’Brien
}

Published online by Cambridge University Press, 04 August 2011

doi: $10.1017 / \mathrm{S} 1041610211001220$

In the Guest Editorial by Frisoni et al. an element in Table 1 (in the right-hand section "Preclinical AD: theoretical stages") contained a misprint. Stage 1 - neurodegeneration should have been indicated by a minus sign not a plus sign.

\section{Reference}

Frisoni, G. B. et al. (2011). Revised NIA-AA criteria for the diagnosis of Alzheimer's disease: a step forward but not yet ready for widespread clinical use. International Psychogeriatrics, 23, 1191-1196. doi:10.1017/S1041610211001220. 